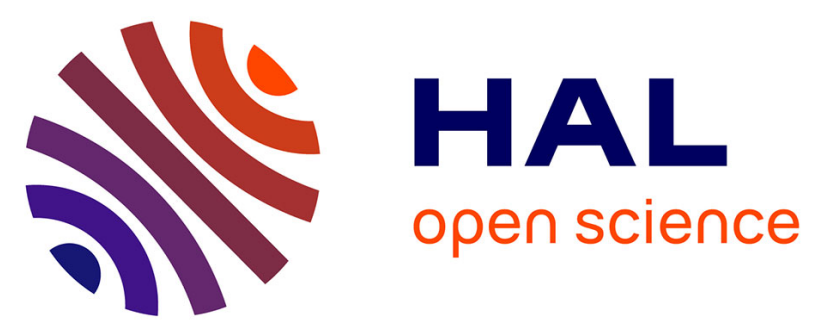

\title{
Analysis of the Potential Benefits of Digital Assembly Instructions for Single and Small Batch Production
}

Frederick Sauermann, Felix Basse, Günther Schuh, Bastian Franzkoch, Jan-Philipp Prote, Melanie Luckert

\section{- To cite this version:}

Frederick Sauermann, Felix Basse, Günther Schuh, Bastian Franzkoch, Jan-Philipp Prote, et al.. Analysis of the Potential Benefits of Digital Assembly Instructions for Single and Small Batch Production. IFIP International Conference on Advances in Production Management Systems (APMS), Sep 2017, Hamburg, Germany. pp.346-353, 10.1007/978-3-319-66923-6_41 . hal-01666220

\section{HAL Id: hal-01666220 https://hal.inria.fr/hal-01666220}

Submitted on 18 Dec 2017

HAL is a multi-disciplinary open access archive for the deposit and dissemination of scientific research documents, whether they are published or not. The documents may come from teaching and research institutions in France or abroad, or from public or private research centers.
L'archive ouverte pluridisciplinaire HAL, est destinée au dépôt et à la diffusion de documents scientifiques de niveau recherche, publiés ou non, émanant des établissements d'enseignement et de recherche français ou étrangers, des laboratoires publics ou privés.

\section{(c)(1)}

Distributed under a Creative Commons Attribution| 4.0 International License 


\title{
Analysis of the potential benefits of digital assembly instructions for single and small batch production
}

\author{
Günther Schuh ${ }^{1}$, Bastian Franzkoch ${ }^{2}$, Jan-Philipp Prote ${ }^{1}$, Melanie Luckert ${ }^{1}$, Frederick \\ Sauermann ${ }^{1}$, Felix Basse ${ }^{1}$ \\ ${ }^{1}$ Laboratory for Machine Tools and Production Engineering (WZL), RWTH Aachen Univer- \\ sity, Aachen, Germany \\ $\{g$. schuh, j.prote, m. luckert, f. sauermann, f.basse\}@wzl.rwth- \\ aachen.de \\ ${ }^{2}$ Ortlinghaus-Werke GmbH, Wermelskirchen, Germany \\ bastian.franzkoch@ortlinghaus.com
}

\begin{abstract}
This paper presents the results of a study that was conducted in the Demonstration Factory Aachen in order to analyze the potential benefits of digital assembly instructions compared to paper-based ones. The aim of this study is to validate three hypotheses regarding the benefits in terms of productivity, quality and learning rate. The results will be used to assess the benefits of a potential rollout of digital assembly instructions in a German mid-size company that assembles multi-variant products in the machining equipment sector.
\end{abstract}

Keywords: Assembly $\bullet$ Digitization $\bullet$ Learning effects

\section{Introduction}

Individualization of products and reduction of lead-times within a production are two of a set of challenges for modern manufacturing companies. Still, high quality remains a crucial factor. Mass production of homogeneous products is increasingly replaced by more customer oriented manufacturing. [1] On the one hand, industrial production still tries to keep the costs low but on the other hand producers seek to serve the needs of the customers by supplying a high variety of products [2]. A big challenge for producers is to chase both goals without losing track of one of them [3]. In order to cope with these challenges, former manufacturing processes have to be revised as a whole [4]. The principles of Industry 4.0 are commonly seen as one of the most promising answers to the demands of a new efficient production [5].

Research in this area is not comprehensive yet, but the following two studies have been carried out. HÖFFLER and LEUTNER give a summary of the research that was done in the field of digital assembly instructions [6]. Having analyzed 24 studies with in total 76 comparisons of the instructional effectiveness of animations and static pictures, they conclude that there is a "substantial overall advantage of animations over static pic-

adfa, p. 1, 2011.

(C) Springer-Verlag Berlin Heidelberg 2011 
tures". How animations have been designed seems to play a major role for the effectiveness of an instructional animation. [7] After this summary, CURRAN et al. conducted a study similar to the one in this paper. However, they did not exclude learning effects in favor of digital instructions from analog ones as their study participants assembled the products with both an analog and subsequently with a digital instruction. [8]

Especially the findings from HÖFFLER and LEUTNER emphasize the relevance of the regarded research question. In order to analyze the benefits of Industry 4.0 at a relatively basic level, a study was conducted researching the effects of using digital assembly instructions in comparison to conventional, paper-based ones in terms of productivity, quality and learning rate. In this study that will be presented in this paper, 24 test persons were asked to assemble penholders using either a digital or an analog assembly instruction and simulating a small batch production. The results have to be seen with caution, considering the number of test persons. Though this study serves as a first pointer for further research, the results suggest high benefits of implementing digital assembly instructions especially for single and small batch production. In the following chapter, the materials and methods used in the study are described.

\section{Materials and Methods}

The study was conducted at assembly stations in the Demonstration Factory Aachen (DFA), in which a transformable production is depicted in a real production environment and in which production systematic and logistical questions are researched on the basis of empirical data. The test persons were students of RWTH Aachen University who also work as student assistants in the Laboratory for Machine Tools and Production Engineering (WZL). None of the test persons knew the test before. In the following, the detailed execution of the tests is described and the underlying hypotheses presented.

\subsection{Description of test execution}

In total 24 students took part in the experiment on ten different dates in the DFA, assembling ten penholders per date using either a digital or an analog assembly instruction. On average, four test persons participated at each date. In order to get background information of the participants on age, field of studies and prior knowledge a questionnaire was handed out. Concerning prior knowledge the participants were asked for a self-assessment compared to their colleagues in terms of experience in assembling, experience in handling CAD programs, abilities in engineering drawing and overall technical abilities each on scale from one (very low) to five (very high). After completing the questionnaire, the test persons had to assemble a penholder by using either a digital assembly instruction or an analog one. A penholder consists of eight steel sheets that are to be assembled with different types of screws in several sizes combined with washers as shown in Fig. 1. The test persons needed to use Phillips and Allen screwdrivers in different sizes. They were told that they would assemble different versions of the penholder in each of the ten rounds. The exact number of variants was not known to the test persons. In fact, there have only been four different versions that differed in the orientation of the components and the selection of screws. 
The paper-based instructions looked like the one shown in Fig. 1. The instructions for the different variants were collected in folders at the assembly stations. When starting the time, each test person got the number of the version to assemble at a desk between the assembly stations. Having got the number, the test person walked to his/her assembly station, looked up the matching instruction and began to assemble the penholder using the components lying on the stations in several signed boxes. After completion, the test person brought the fully assembled penholder back to the starting point, checking the time again. Subsequently, the penholder was inspected on defects.

The test persons with the digital assembly instructions were handed a laminated sheet of paper with a Radio Frequency Identification (RFID) tag on its back, which is used to communicate with a sensor above the assembly station. Placing this sheet of paper on the sensor, the digital instruction was automatically loaded on a touch screen according to the matching version. The digital instructions consisted of step-by-step animations with a list of c-parts and highlighted the right parts to assemble in a special color on a tablet screen. By touching the screen, the test persons could switch between the assembly steps and were able to turn the images in three dimensions.

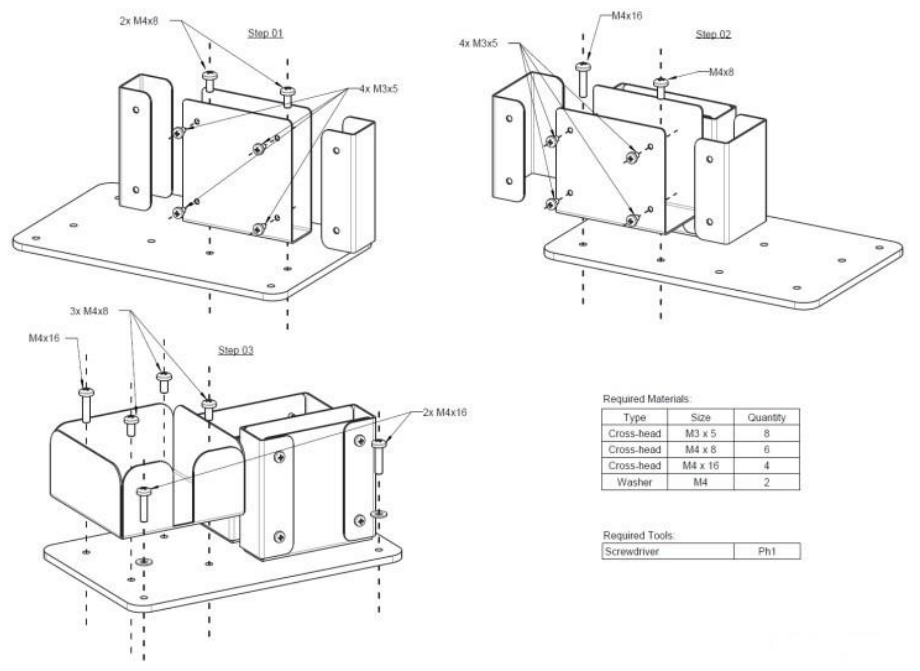

Fig. 1. Example of a variant of the penholder

The group of participants consisted of 24 people being on average 22.2 years old. 21 test persons were male and three female. Half of the test persons were provided with digital assembly instructions and the other half got paper-based ones.

The participants were composed of students from the fields of mechanical engineering $(25 \%)$, industrial engineering $(50 \%)$ and scientific programming $(25 \%)$. They were asked to give a self-assessment about several aspects on a scale from 1 (very low) to 5 (very high). With regard to the assessment of the technical skills, the values of the mechanical engineering students were with 2.83 just slightly higher than those of the industrial engineering students with 2.67 . The students of scientific programming assessed their skills with a value of 1.64 substantially lower. The allocation of the analog 
and digital instructions to the group of participants was done randomly. However, the self-assessment of the technical skills in the group with the digital instructions was on average $35 \%$ higher than in the group using the analog one, which all scientific programmer were part of.

\subsection{Hypotheses of the benefits}

Before the study was carried out, three qualitative hypotheses were proposed for the expected results with regard to the improvement of the benefits in terms of (1) productivity, (2) quality and (3) learning rate (see Fig. 2). The first hypothesis states that the productivity of assembling a variant with a digital assembly instruction is higher than with an analog one with regard to lead-time. The second hypothesis is that the number of errors per assembled penholder is lower when the penholder is assembled using a digital assembly instruction. As a third hypothesis it was formulated that assemblers are quicker to learn how to assemble the penholders when using a digital assembly instruction, being quantified by using the learning rate. The learning rate describes the inverse relationship between costs per unit and number of units being produced. In the study, a proportional relationship between lead-time and costs per unit is assumed. Even though the quality of the products produce it is not represented in this figure, it still has to be kept in mind when assessing the learning rate.

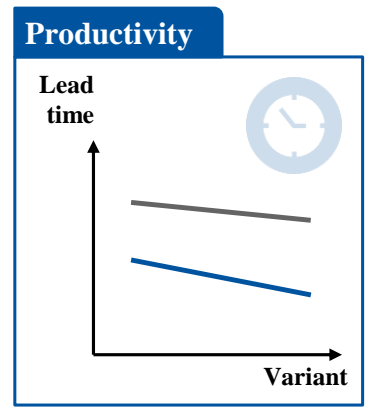

— Digital Assembly Instruction

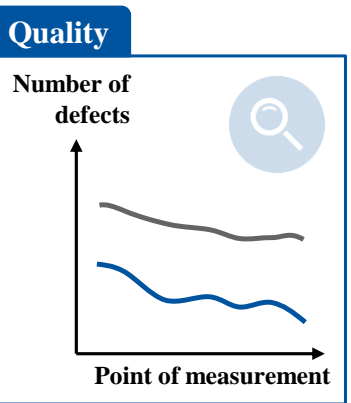

- Analog Assembly Instruction

\section{Learning rate}

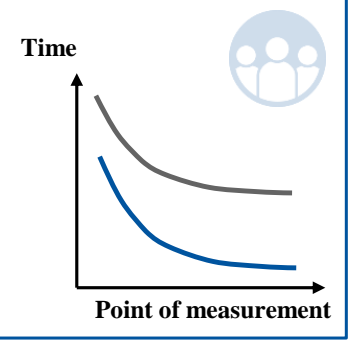

Fig. 2. Hypotheses

\section{$3 \quad$ Results and Discussion}

In the following, the results will be presented. Subsequently, the findings based on the results will be discussed.

\subsection{Results}

Before analyzing the data in depth, the sample is checked on outlier. Analyzing the defects it becomes obvious that there is one outlier in the group of participants using the digital assembly instruction. While the assemblers in the group of study participants 
using the analog instruction were a homogeneous group with a standard deviation of 1.19 with regard to quality, the group of participants using the digital instruction had one member who made disproportionately many mistakes resulting in a standard deviation of 2.6 for this group. Excluding this participant for the analysis of the data, the standard deviation drops from 2.6 to 1.24 , which is close to the 1.19 of the other group. Hence, it makes sense from a statistical point of view to analyze the data excluding the outlier. The following results have arisen concerning the three hypotheses of productivity, quality and learning rate after excluding the outlier in the analysis.

The study confirms the expected outcome of a higher productivity when using a digital assembly instruction compared to the analog one (see Fig. 3). Assembling the first penholder, the study participants with the analog instruction needed on average $31.2 \%$ more time (in total 12 minutes and 51 seconds) than the participants did with the digital one ( 9 minutes and 48 seconds). Even though the difference became smaller with the number of penholders assembled, the results for the digital assembly instruction were for the last five points of measurement on average still $14.9 \%$ better. Overall, the productivity of the analog assembly instruction was $17.0 \%$ worse, meaning that assemblers needed on average 01:01 minutes more time per piece.

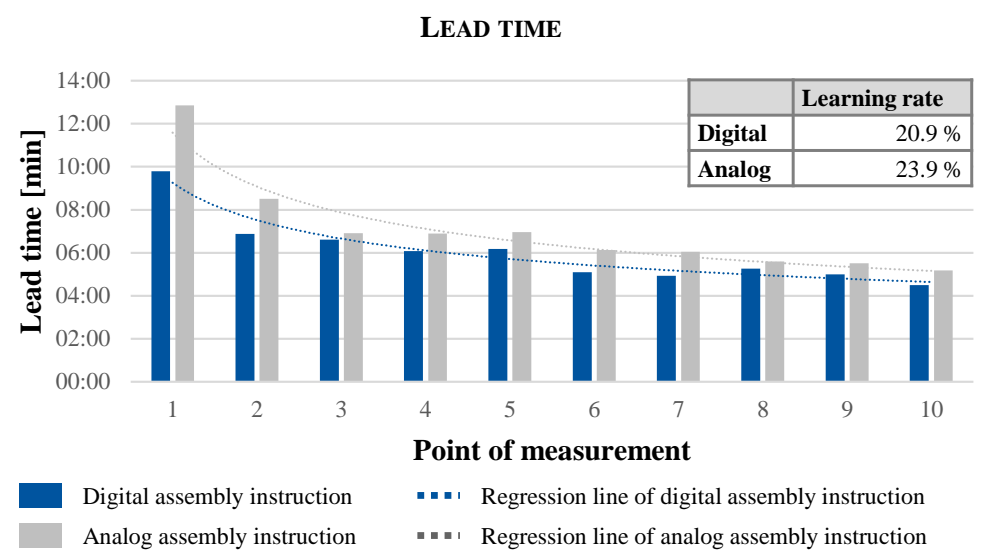

Fig. 3. Development of lead time

Before going into the analysis of the results, it is important to understand the performance indicator used to describe the quality. Instead of using the simple number of defects per unit, the defects are weighted based on their severity. For example, using a wrong screw (e.g. different length) is less important for a penholder than a wrong position of the objects on the main plate (e.g. the container). Hence, the defects are weighted with factors from one to three.

Analyzing the plain data, the outcome was that the weighted number of defects was 96 defects for the analog assembly instruction while using a digital one resulted in 76 defects. Overall, the numbers mean on average 0.8 defects per assembled penholder for the analog assembly instruction and 0.69 for the digital one, which leads to the conclusion that the hypotheses can be confirmed as well. The outlier of weighted defects in 
the second point of measurement of the digital instruction can be explained by a high number of mistakes made by one test person. Comparing these figures, the study shows that the former group made on average $15.7 \%$ more defects per penholder than the group with a digital assembly instruction. Additionally, it can be seen in the study that in case of using a digital instruction the last $80 \%$ of the assembled penholders had only $6.6 \%$ of the total number of defects, whereas the analog instruction had in the same timeframe $26 \%$ of the total defects of the analog one. Directly comparing the absolute numbers, the group of assemblers with the analog instruction made five times more defects in this timeframe. For the first $20 \%$ of the assembled products the ratio between the two kinds of assembly instruction is 1:1. These findings can be explained by the hypothesis, that a digital assembly instruction helps assemblers to understand the way of assembling the product better and more sustainably than the analog one.

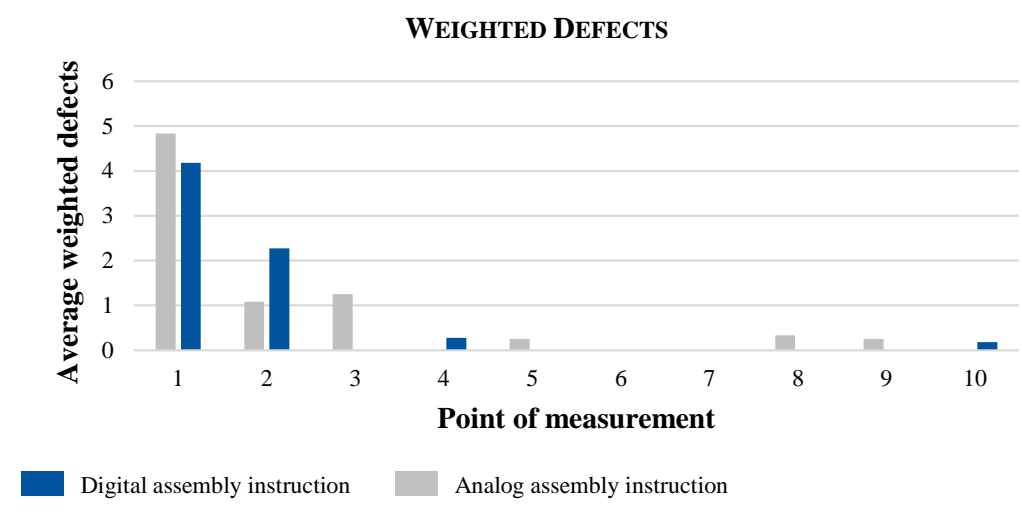

Fig. 4. Weighted defects

While the first two hypotheses can be confirmed, the last hypothesis concerning the learning effects has to be rejected. As can be seen in Fig. 3, the learning rate of assemblers using the digital assembly instruction was $20.9 \%$ whereas the assemblers with an analog instruction had a learning rate of $23.9 \%$. This means that for every doubling of the number of penholders having been produced the costs per unit fell on average on $79.1 \%$ of the initial value of the assembly costs when using a digital instruction. Hence, the analog assembly instruction seems to be about three percentage points better with regard to the learning effects. However, taking quality in consideration when assessing this figure, the advantage of analog instructions declines.

\subsection{Discussion}

The results confirm two of the three hypotheses, if the outlier in the analysis of the quality is excluded. Still, it has to be pointed out that the number of participants in the study was small. Conducting the study with a higher number, the influence of the outlier on the results would have been less significant. With the number of participants being small, the results have to be seen critically. Especially the fact that the number of 
weighted defects of the last $80 \%$ of assembled products account only for $17.4 \%$ of the total number of defects and with $89.1 \%$ of all assembled products being flawless, indicates that the wealth of variants of the penholder was too low for the participants. On the other hand, those numbers can show that a digital assembly instruction helps to improve quality significantly compared to an analog one, when assembling similar products in high quantity.

Concerning the productivity, the results indicate that a digital assembly instruction has a significant potential of reducing the lead-time per unit. In particular, the study shows that the potential is even more promising, the more variants are assembled with a small number of totally assembled products as the difference in the lead-time is at the beginning substantially higher. This finding is especially interesting for companies with small lot sizes, i.e. companies in the single and small batch size industry, and companies having a high employee turnover. Considering current developments of shorter product life cycles, this advantage of the digital assembly instruction is even more promising even for other industries.

As stated in chapter 2.1, all scientific programmers assembled the penholder using an analog instruction. With their self-assessment being as low as 1.64 compared to the 2.67 and 2.83 respectively, one might expect worse results for this group of participants. However, this is only the case in terms of quality but not in terms of lead-time. Having assembled almost twice as much defects $(64.6 \%$ of the total amount of defects in the group of participants using the analog instruction), they were as fast as the other part of the group with just one second less of the overall time needed. If the digital assembly instruction truly helps to understand the way of assembling products better and more sustainably as stated in chapter 3.1 , needs to be further researched.

Having a look at the test execution, it has to be stated that there was a difference of the position of the assembly instruction. Whereas the analog one lied on the assembly table next to the components that were to be assembled, the screen for the digital one hung in front of the assemblers. Moving down the screen to the position of the analog instruction could lead to even better results of the digitally instructed products.

\section{Conclusion}

In times of an increasing amount of variants and shorter product life cycles, a study was conducted in order to analyze the potential of digital assembly instructions compared to analog ones in the closed environment of the DFA. Besides researching the consequences on lead-time and learning effects, the study observed the quality of the assembled products, in order to prevent a potential loss of quality in favor of lead-time.

As expected and formulated in the hypotheses, the study proved that digital assembly instructions lead to a rise in the productivity of the assemblers compared to their colleagues with analog instructions. Excluding one outlier from the test data of the digital assembly instruction, the study proved furthermore that a digital assembly instruction helps assemblers to assemble products not only faster but also with less defects in both short- and long-term perspective. In terms of learning effects, the analog assembly instruction showed better results, which is caused by high initial lead-times compared to 
the ones that used digital one. Hence, it is to further research under which conditions digital assembly instructions should be used, taking into consideration, that deriving digital instructions can be expensive in the single and small batch industry, it is to analyze how a critical number of products per variant can be determined to assess the economical suitability. By an increasing complexity of products, this question becomes even more relevant considering the advantages in terms of efficiency and quality.

With the number of participants being small, further research needs to be done to validate the results. In cooperation with the German mid-size company OrtlinghausWerke $\mathrm{GmbH}$ this will be done in their assembly lines in the plant Wermelskirchen.

\section{Acknowledgements}

The project, on which this report is based, is supported and realized by "Digital in NRW. The Competence Centre for SME in North Rhine-Westphalia". The Competence Centre is part of the funding initiative "SME 4.0 - Digital Production and Work Processes", which is funded as part of the research priority on "SME-Digital - Strategies for the Digital Transformation of Business Processes" by the German Federal Ministry of Economics and Energy.

\section{References}

1. Blecker T, Friedrich G (eds) (2006) Mass Customization: Challenges and Solutions. International Series in Operations Research \& Management Science, vol 87. Springer Science+Business Media Inc, Boston, MA

2. Schuh G (ed) (2015) Leitfaden zur Baukastengestaltung: Ergebnisse des Forschungsprojekts Gestaltung innovativer Baukasten-und Wertschöpfungsstrukturen (GiBWert). VDMA-Verl., Frankfurt, M.

3. Alptekinoğlu A, Corbett CJ (2010) Leadtime-variety tradeoff in product differentiation. Manufacturing \& service operations management : M \& SOM 12(4): 569-582

4. Schuh G, Pitsch M, Komorek N (2015) Fast Forward Factory, 1. Edition. WZL; RWTH Aachen, Aachen

5. Felser W (ed) (2015) Industrie 4.0 kompakt. Competence Book. NetSkill Solutions, Köln

6. Höffler TN, Leutner D (2007) Instructional animation versus static pictures: A meta-analysis. Learning and Instruction 17(6): 722-738. doi: 10.1016/j.learninstruc.2007.09.013

7. Michas IC, Berry DC (2000) Learning a procedural task. Applied Cognitive Psychology 14(6): 555-575. doi: 10.1002/10990720(200011/12)14:6<555:AID-ACP677>3.0.CO;2-4

8. Curran R, Chou S-Y, Trappey A (eds) (2008) Collaborative Product and Service Life Cycle Management for a Sustainable World: Proceedings of the 15th ISPE International Conference on Concurrent Engineering (CE2008). Advanced Concurrent Engineering. Springer, London, Heidelberg 